\title{
Tungsten (W) Laminate Pipes for Innovative High Temperature Energy Conversion Systems**
}

By Jens Reiser,* Michael Rieth, Anton Möslang, Henri Greuner, David E. J. Armstrong, Thorsten Denk, Tim Gräning, Wolfgang Hering, Andreas Hoffmann, Jan Hoffmann, Harald Leiste, Tobias Mrotzek, Reinhard Pippan, Werner Schulmeyer, Tobias Weingärtner and Anton Zabernig.

[*] Dr. J. Reiser,* Dr. M. Rieth, Dr. A. Möslang, T. Gräning, Dr. W. Hering, Dr. J. Hoffmann, Dr. H. Leiste, T. Weingärtner

Karlsruhe Institute of Technology, Institute for Applied Materials, 76344 Eggenstein-

Leopoldshafen, Germany

E-mail: jens.reiser@kit.edu)

H. Greuner

Max Planck Institute of Plasma Physics, Garching, Germany

Dr. D. E. J. Armstrong

University of Oxford, Department of Materials, United Kingdom

T. Denk

Plataforma Solar de Almería - Ciemat, Spain

Dr. A. Hoffmann, Dr. T. Mrotzek, Dr. W. Schulmeyer, A. Zabernig

PLANSEE SE, Reutte, Austria

Prof. R. Pippan

Austrian Academy of Science, Leoben, Austria

[**] Financial support by the Access to Research Infrastructures activity in the 7th Framework Programme of the EU (SFERA Grant Agreement n. 228296) is gratefully acknowledged. This work, supported by the European Community, was carried out within the framework of the European Fusion Development Agreement. The views and opinions expressed herein do not necessarily reflect those of the European Commission.

The authors are grateful to their colleagues from PLANSEE SE, the University of Oxford, the Austrian Academy of Science, the IPP Garching, Plataforma Solar de Almería and the Karlsruhe Institute of Technology for their support and valuable contributions. The contributions of J. R. Garcia, I. C. Martinez (Plataforma Solar de Almeria), Dr. W. Knabl (PLANSEE SE), and Dr. S. Wurster (Austrian Academy of Science) are gratefully acknowledged.

\section{Abstract}

The aim of this paper is to present the mechanical properties of tungsten laminate pipes made of tungsten foil and to discuss their use in innovative high temperature energy conversion systems.

Tungsten is the metal with the highest melting point of all metals and would therefore be an excellent fit for high temperature applications. But tungsten has one major drawback which is its low fracture toughness at room temperature (RT) or its high brittle-to-ductile transition 
temperature (BDTT). However, one of the extraordinary properties of tungsten is that by cold working the BDTT can be shifted to lower temperatures. At the extreme, this results in a tungsten foil with a BDTT below $-120^{\circ} \mathrm{C}$ combined with a RT fracture toughness of $70 \mathrm{MPa}$ $\mathrm{m}^{1 / 2}$.

By rolling up and joining a tungsten foil, tungsten laminate pipes can be synthesized that can dissipate at least $20 \mathrm{~J}$ in a Charpy impact test at RT and survive a burst test at RT at 1000 bar without any residual damage. The technical maturity of these $\mathrm{W}$ laminate pipes is approved by high heat flux tests performed at the Plataforma Solar de Almería, Spain, as well as at the Max Planck Institute of Plasma Physics, Garching, Germany.

\section{Introduction}

Tungsten $(\mathrm{W})$ is a metal of superlatives as it has the highest melting point of all metals $\left(\mathrm{T}_{\mathrm{m}}=\right.$ $3422^{\circ} \mathrm{C}$ ), excellent high temperature strength and high creep resistance. On the other hand, tungsten has two major disadvantages: poor oxidation resistance at temperatures above $600^{\circ} \mathrm{C}$ as well as a low room temperature (RT) fracture toughness, $\mathrm{K}_{\mathrm{IQ}}$, and a brittle-to-ductile transition (BDT) that, unfortunately, occurs at high temperatures. This is why tungsten is only used as a functional material and not as a structural material, that is, not for safety relevant, pressurized parts. Consequently, thinking about tungsten as a structural material, the question of how to make tungsten ductile and how to decrease the brittle-to-ductile transition temperature (BDTT) arises.

The approach assessed by the authors is the ductilization of tungsten through the synthesis of a tungsten foil laminate, a multilayer material, made of ultra-fine grained (UFG) W foil. The idea is to make use of one of the unique properties of $\mathrm{W}$ (and also of molybdenum (Mo)) that is that the BDTT can be shifted to lower temperatures through cold working. Putting this to its extreme results in a $\mathrm{W}$ foil with a BDTT below $-120^{\circ} \mathrm{C}$ (foil, $100 \mu \mathrm{m}$; strain rate $3^{*} 10^{-3} \mathrm{~s}^{-1}$ ) 
and a RT fracture toughness of $70 \mathrm{MPa} \mathrm{m}^{1 / 2}$ (T-L). Through the synthesis of tungsten laminates made of $\mathrm{W}$ foils it is possible to expand the extraordinary properties of the foil to the bulk and to shift the BDT of up to $300^{\circ} \mathrm{C}$ to lower temperatures compared to pure tungsten plate material. ${ }^{[1]}$ Furthermore, by rolling up and joining, a W laminate pipe can be produced that appears to be an interesting candidate for high temperature applications in the field of innovative energy conversion systems (Figure 1).

The evolution of high temperature materials for structural applications (e.g. in form of pipes) ranges from (i) steels over (ii) Ni-base super alloys up to so-called (iii) "beyond Ni-base super alloys”. The criteria for these materials are high creep strength (100 MPa, $\left.10^{5} \mathrm{~h}\right)$, stability of the microstructure, oxidation resistance and the availability of a suitable joining technology. Up to the ninetieth, X20 steels (11-12 wt. \% chromium (Cr)) were state-of-the-art steels for pipes with operation temperatures up to $565^{\circ} \mathrm{C}$. Thereafter, and within the framework of the European COST 501 program (1983-1997), the creep resistance of 9 wt. \% Cr steel was enhanced by adding Mo and/or W (P91, 1.4903, X10CrMoVNb9-1; E911, 1.4905, X11CrMoWVNb9-1-1; P92, 1.4901, X10CrWMoVNb9-2) resulting in an operation temperature of up to $600^{\circ} \mathrm{C}$. In the next step and within the framework of the COST 522 program (1998-2003), operation temperatures of up to $625^{\circ} \mathrm{C}$ were reached by $11-12 \mathrm{wt}$ \% Cr steels by adding cobalt (Co, up to 3 wt. \%) and boron (B, up to 0.01 wt. \%). These high performance 9-12 wt. \% Cr steels presented here do all consist of a fully martensitic matrix with fine dispersed carbides obtained by hardening and tempering.

In order to reach a plant efficiency factor of more than $50 \%$, current research activities are trying to realize an operation temperature of $700^{\circ} \mathrm{C}$ by using nickel $(\mathrm{Ni})$ base super alloys such as $2.4663-\mathrm{NiCr} 23 \mathrm{Co} 12 \mathrm{Mo}$. The melting point of $\mathrm{Ni}$ is $1455^{\circ} \mathrm{C}$ (compared to $\mathrm{W}: \mathrm{T}_{\mathrm{m}}=$ $3422^{\circ} \mathrm{C}$ ) and its homologous temperature $\left(773 \mathrm{~K} / \mathrm{T}_{\mathrm{m}}\right)$ is 0.45 (compared to $\mathrm{W}: 0.21$ ). Such exceptionally high homologous operating temperatures can only be reached by coherent $\gamma^{\prime}-$ 
phase precipitation hardening, which is unique to Ni base alloys. In addition, the corrosion resistance of $\mathrm{Ni}$ base alloys can be significantly improved by the addition of $\mathrm{Cr}$ and aluminum (Al).

Beside steels and Ni-base super alloys, there are so-called "beyond Ni-base super alloy" material systems. Regarding the technical readiness, these materials are either on the scientific development level or face serious problems, such as costs, large scale production, and oxidation among others. Molybdenum (Mo), for example, or the hardened Mo-alloy TZM (Mo base, 0.5 wt. \% Ti, 0.08 wt. \% Zr, $0.01-0.04$ wt. \% C) is prone to oxidation. This drawback can be overcome by either using protection layers of silicon ( $\mathrm{Si}$ ), B, or by Mo-Si-B compounds. ${ }^{[2,3,4]}$ In addition, the discussion includes oxide dispersion strengthened (ODS) steels (austenitic ${ }^{[5,6]}$, ferritic ${ }^{[7,8]}$ and ferritic-martensitic ${ }^{[9]}$ ), directionally solidified NiAl-X (Cr, Mo) eutectics ${ }^{[10,11,12,13]}$, Co-Re alloys ${ }^{[14,15]}$, and silicon carbide $(\mathrm{SiC})^{[16,17]}$ or carbonfiber-reinforced silicon carbide $(\mathrm{C} / \mathrm{SiC})$. Within the current discussion of the "beyond Ni-base super alloys”, the authors want to include tungsten laminates as a new innovative material system.

\section{Background}

Tungsten belongs to the refractory metals that are commonly defined as the metals of group Va (5) and VIa (6) with a melting point above $2000^{\circ} \mathrm{C}$, meaning niobium (Nb), tantalum (Ta), molybdenum (Mo) and tungsten (W). In some publications, rhenium (Re) is included. On average, the Earth's crust contains around $1.25 \mathrm{~g}_{\text {tonne }}{ }^{-1}$ of tungsten.

In general, W semi-finished products are produced in a powder metallurgical process consisting of mixing, pressing and sintering of the W powder followed by forming, such as hot and cold rolling. The W powder can be obtained from minerals or ore, such as Ferberite $\left(\mathrm{FeWO}_{4}\right)$, Hubnerits $\left(\mathrm{MnWO}_{4}\right)$, Wolframite $\left((\mathrm{Fe}, \mathrm{Mn}) \mathrm{WO}_{4}\right)$ and Scheelite $\left(\mathrm{CaWO}_{4}\right)$ by 
separating it from the by-products by crushing and flotation. The final tungsten powder can then be obtained by hydrogen reduction of ammonium paratungstate $\left(\left(\mathrm{NH}_{4}\right)_{2} \mathrm{WO}_{4}\right)$, tungsten oxide $\left(\mathrm{WO}_{3}\right)$ and tungsten blue oxide $\left(\mathrm{WO}_{3-\mathrm{x}}\right) .^{[18,19]}$

Tungsten shows chemical passive behavior towards gases such as carbon dioxide $\left(\mathrm{CO}_{2}\right)$ or carbon monoxide (CO) as well as towards molten salts and molten metals like lead (Pb, up to $1100^{\circ} \mathrm{C}$ ), bismuth (Bi, up to $1400^{\circ} \mathrm{C}$ ) or sodium (Na, up to $1100^{\circ} \mathrm{C}$ ). Besides having a high melting point, $\mathrm{W}$ has high thermal conductivity of $164 \mathrm{~W} \mathrm{~m}^{-1} \mathrm{~K}^{-1}$ at $\mathrm{RT}$, a low thermal expansion coefficient of $4.2 * 10^{-6} \mathrm{~K}^{-1}\left(\mathrm{RT}-100^{\circ} \mathrm{C}\right)$, and a nearly isotropic YOUNG's Modulus of $410000 \mathrm{MPa}$ at RT. ${ }^{[18,19]}$

Like all other body-centered cubic metals, W exhibits a BDT meaning that the material is brittle at low temperatures and ductile at elevated temperatures. This BDT depends on the strain rate and is such that the higher the strain rate the higher the BDTT, making the Charpy impact test a conservative test method. ${ }^{[20,21]}$ Tungsten has some extraordinary mechanical behaviors in that it behaves unlike most other metals. One of the most important and fascinating exceptions is that the BDTT of W (and also of Mo) can be shifted to lower temperatures by cold working. It is well known that cold working increases the strength as it increases the dislocation density and decreases the grain size ${ }^{[22,23]}$ but in $\mathrm{W}$ it also decreases the BDTT. A second extraordinary mechanical property of $\mathrm{W}$ is its low cohesion of high angle grain boundaries (HAGBs) leading to preferred intergranular fractures. And finally, different from other metals, the underlining microstructure, such as the grain size and grain shape, has a strong impact on the fracture behavior of $\mathrm{W}$ resulting in the anisotropic fracture toughness of polycrystalline W materials. ${ }^{[24,25]}$

Compared to molybdenum, tungsten is less intensely investigated. Up to now, the scientific assessment of tungsten has mainly focused on the influence of impurities on the low HAGBs 
cohesion, ${ }^{[26,27]}$ the $45^{\circ}$ embrittlement, ${ }^{[28]}$ the fracture behavior and strain rate dependence of W single crystals as well as the determination of the controlling mechanism of the BDT. ${ }^{[20,29,30,31]}$ Some authors admit that the fracture behavior of tungsten has been very well studied for single crystals and that the results can well be interpreted for such simple microstructures but that the understanding of more complicated microstructures, like textured and possibly pre-deformed polycrystalline materials, is far less well understood. ${ }^{[21]}$

The assessment of ductilice tungsten mainly focuses on three approaches. The first approach consists of the synthesis of a tungsten solid solution according to the example of tungstenrhenium (WRe). Tungsten with at least 7 wt. \% rhenium is meant to shift the BDTT to lower temperatures. It is expected, that rhenium changes the core of a screw dislocation from symmetric to asymmetric, reducing the PEIERLS barrier and making the screw dislocations move more easily. ${ }^{[32,33]}$ However this effect does not seem to take place for tungstenvanadium (WV), tungsten-tantalum (WTa) and tungsten-molybdenum (WMo) solid solutions. ${ }^{[32,33,34,35]}$ A second approach is the synthesis of a tungsten material with a UFG microstructure realized by either severe plastic deformation (SPD) via high pressure torsion $(\mathrm{HPT})^{[36,37]}$ or by mechanical alloying. ${ }^{[38,39]}$ The third approach finally makes use of the synthesis of a W compound that can either be reinforced by particles, ${ }^{[40]}$ randomly distributed short fibers $^{[41]}$ or uniaxial long fibers. ${ }^{[42]}$

Summarizing, it can be concluded, that pure tungsten is the most ductile tungsten (measured by Charpy, with the exception of WRe and maybe tungsten-iridium (WIr)).

The authors approach to ductilice tungsten is the synthesis of a $\mathrm{W}$ laminate made of $\mathrm{W}$ foil. As described above, the BDTT of W can be shifted to lower temperatures by cold working. So, an extreme example of a semi-finished product being subjected to a high degree of cold work is tungsten foil. The BDTT of a technically pure and $100 \mu \mathrm{m}$ thick $\mathrm{W}$ foil in the asreceived condition is below $-120^{\circ} \mathrm{C}$ (strain rate $3^{*} 10^{-3} \mathrm{~s}^{-1}$, sample without notch). 
Furthermore, the fracture toughness, of forged W 26 wt. \% Re is $54.2 \mathrm{MPa} \mathrm{m}^{1 / 2}$ at RT (L-R orientation). ${ }^{[43]}$ As can be seen in Figure 2 the fracture toughness, KIQ , at RT of technically pure and $160 \mu \mathrm{m}$ thick $\mathrm{W}$ foil is anisotropic and has a value of at $70 \mathrm{MPa} \mathrm{m}^{1 / 2}$ in L-T, $55 \mathrm{MPa}$ $\mathrm{m}^{1 / 2}$ in T-L, and 1.5 MPa $\mathrm{m}^{1 / 2}$ in S-L orientation (details on the two-letter code can be found elsewhere $\left.{ }^{[44]}\right) .{ }^{[45]}$ While in the case of W 26 wt. \% Re the high fracture toughness results from the formation of a W solid solution, in the case of pure tungsten foil it is only related to its UFG microstructure. The authors now make use of these tungsten foils and expand the extraordinary properties of the foil to the bulk through the synthesis of a tungsten laminate material, a multilayer material. Doing this, it is possible to shift the BDTT of up to $300^{\circ} \mathrm{C}$ (semi-finished products in the as-received condition) and $500^{\circ} \mathrm{C}$ (semi-finished products in the recrystallized condition) to lower temperatures compared to pure tungsten plate material. ${ }^{[1]}$

The discussion about the unique mechanical properties of $\mathrm{W}$ foil and $\mathrm{W}$ laminates is always a discussion about UFG materials and size effects. Among the size effects, the microstructural and dimensional size effects can be distinguished. ${ }^{[46]}$ Microstructural size effects, for example, have to be considered in discussing the mechanism of plastic deformation leading to the extraordinary RT ductility of $100 \mu \mathrm{m}$ tungsten foil. In the as-received condition, this foil has a pancake-shaped grain with a dimension of $0.5 \times 3 \times 15 \mu \mathrm{m}^{3}$ so the grain size in the direction of the thickness is in the so-called intermediate grain size regime. ${ }^{[47]}$ While the plasticity of coarse grained materials (grain size $>1 \mu \mathrm{m}$ ) is controlled by unit dislocations and work hardening, and the mechanism of deformation of nanocrystalline materials (grain size < $100 \mathrm{~nm}$ ) is believed to be grain-boundary shear, the mechanism of plastic deformation of materials with grain sizes in the so-called intermediate regime (grain size $100 \mathrm{~nm}-1 \mu \mathrm{m}$ ) is less well understood but is thought to affect ductility significantly. ${ }^{[48]}$ 
Another extreme microstructure of the $\mathrm{W}$ foil can be obtained by annealing the tungsten foil for $1 \mathrm{~h}$ at $2700^{\circ} \mathrm{C}$. This results in a microstructure of only one grain over the thickness of the foil. If this foil is stressed during, for example, a tensile test, the activated dislocations can glide without any grain-boundary obstacle and can move to the free foil surface where they are annihilated. This mechanism of dislocation annihilation results in an enhanced plastic deformability in a tensile test of up to $40 \%$ plastic strain combined with serrated flow. ${ }^{[49]}$ A second point where size effects do have to be taken into account is the discussion about the fracture toughness of tungsten foil. First, there is a statistical reason why foils show higher fracture toughness than bulk material as, in thin layers, the statistical possibility of a significant defect is lower. But, furthermore, there is also a thickness dependence on the fracture toughness being linked with the stress-strain distribution in the bulk or foil. ${ }^{[50]} \mathrm{A}$ valid measurement of the fracture toughness, $\mathrm{K}_{\mathrm{IC}}$, in the sense of the ASTM 399 standard, for example, requires a condition of plane strain. ${ }^{[44]}$ A plane stain condition generates, in general, in the middle section of a test sample; the sample edges are governed by plane stress. Looking at tungsten foil, the plane stress condition is likely to govern the whole thickness of the foil meaning that a valid measurement of the fracture toughness according to the standard is not likely to be possible for foils due to their size.

The second type of size effects are dimensional size effects that can be created by synthesizing a $\mathrm{W}$ laminate with an interlayer with a thickness of less than $1 \mu \mathrm{m}$, a so-called thin film laminate. In this case, the glide of the dislocations in the interlayer is dimensionally constrained as they are channeled between two interfaces. If the interlayer of such a laminate is plastically deformed, dislocation channeling might occur leading to enhanced strength of the laminate. ${ }^{[46,51]}$ One possible laminate candidate where dislocation channeling is likely to be realized is tungsten-copper laminate with very thin copper interlayers. Joining tungsten foils with copper leads to excellent sharp interfaces as there is excellent wettability of both materials but nearly no diffusion of copper in tungsten and vice versa. 
Considering all these aspects makes tungsten laminates an interesting material for fundamental material research but also for technical applications as there are applications in innovative energy conversion systems where tungsten laminate pipes might enhance the performance.

One example is concentrated solar power (CSP). In contrast to photovoltaics, CSP uses large fields of mirrors to increase significantly the thermal radiation flux before its conversion within a technical system. ${ }^{[52]}$ Basically, two types of plants exist, on the one hand the medium temperature $\left(<450^{\circ} \mathrm{C}\right) /$ medium (or line) concentration $\left(<100 \mathrm{~kW} \mathrm{~m}^{-2}\right)$ systems, mostly realized as parabolic trough systems, and on the other hand the high temperature $\left(>450^{\circ} \mathrm{C}\right) /$ high (or point) concentration (500 to $2000 \mathrm{~kW} \mathrm{~m}^{-2}$ and more) systems, like solar towers, dishes, or solar furnaces. ${ }^{[53]}$ The conversion of the highly concentrated solar radiation is done by the so-called receiver that mainly consists of a black colored surface, called the absorber, that absorbs the radiation, converts it into heat, and finally transfers it onto a heat transfer fluid.

The most common receiver type is the tube-receiver. Tower systems use heat transfer fluids like water/steam $\left(310-450^{\circ} \mathrm{C}\right)$, molten salt $\left(565^{\circ} \mathrm{C}\right),{ }^{[54]}$ or pressurized air $\left(>900^{\circ} \mathrm{C}\right),{ }^{[55]}$ whereas dish/Stirling engines use helium or hydrogen $\left(650^{\circ} \mathrm{C}\right)$ respectively. ${ }^{[56]}$ Especially for the three latter ones, due to the elevated temperature, tungsten laminate pipes are an interesting alternative for the presently used nickel-base super alloys pipes.

In the future, CSP will be used also for the production of storable fuels like hydrogen $\left(\mathrm{H}_{2}\right)$ or syngas, ${ }^{[57]}$ and for industrial endothermic process technology. A promising pathway for the solar production of hydrogen is solar water $\left(\mathrm{H}_{2} \mathrm{O}\right)$ splitting via a two-step thermochemical cycle using a metal oxide (MO) redox system ${ }^{[58,59,60,61]}$ according to the following equations: 
$\mathrm{H}_{2} \mathrm{O}+\mathrm{MO}_{\text {red }} \rightarrow \mathrm{MO}_{\mathrm{ox}}+\mathrm{H}_{2}$

$\mathrm{MO}_{\text {ox }} \rightarrow \mathrm{MO}_{\text {red }}+1 / 2 \mathrm{O}_{2}$.

For these applications, solarized chemical reactors like fixed beds, fluidized beds, ${ }^{[62]}$ rotary kilns, and so forth are needed and operated at temperatures well above $1000^{\circ} \mathrm{C}$. Solar power is introduced into the reactor through a transparent quartz window or a highly heat resistant opaque plate. For the reactor walls, and possible internals, tungsten laminates might be a good choice, especially if the reaction is performed under reducing conditions.

The general trend of all innovative highly efficient energy systems is to higher temperatures and pressures; especially in concentrating solar power which allows thermal energy to be stored much more cheaply than electrical. ${ }^{[63]}$ However, with most of the heat transfer fluids high temperatures are associated with high pressures; both touch technical and financial limits. Another approach proposed for concentrating solar power plants is to use liquid metals, which can operate at ambient pressures up to $800^{\circ} \mathrm{C}$. Going beyond that value, the direct conversion system based on liquid metal technology called AMTEC (alkali metal thermal energy convertor ${ }^{[64,65]}$ opens a new window to high efficient solar power conversion systems (PCS). AMTEC makes use of the fact that the $\beta$ '’-alumina solid electrolyte (BASE) conducts sodium ( $\mathrm{Na}$ ) only as $\mathrm{Na}^{+}$ions and the reaction

$\mathrm{Na}$ (liquid) $\rightarrow$ electron $+\left[\mathrm{Na}^{+}\right] \mathrm{BASE}$

occurs at the liquid sodium-BASE interface when sodium flows. ${ }^{[64]}$ AMTEC is foreseen as a topping system using the temperature range between $600^{\circ} \mathrm{C}$ to $1000^{\circ} \mathrm{C}$. At the cold side of AMTEC, the excess energy is available for a commercial PCS with turbine entry temperatures 
up to $600^{\circ} \mathrm{C}{ }^{[66]}$ AMTEC operates at ambient pressure and has a modular structure allowing modules to be stacked up to the desired power level. To enhance efficiency the coupling to the power conversion system is done by a thermal storage device, which in turn allows for continuous steady state 24/7 operation. Due to their excellent behavior against molten metals, tungsten and molybdenum are considered as primary candidate for the high temperature section of AMTEC. AMTEC uses a ceramic electrolyte, BASE, which has to be joined to metallic structures, made of, for example, tungsten. Such joints have to be investigated in the future to assess the application range of the novel tungsten laminates presented in this paper. Liquid metal systems and AMTEC are investigated at the Karlsruhe Institute of Technology (KIT) at the Karlsruhe Sodium Laboratory (KASOLA). ${ }^{[67,68]}$

Furthermore, tungsten laminate pipes might enhance the performance of the production of biomass-to-liquid (BTL) fuels. BTL fuels of the second generation such as kerosene, diesel and gasoline offer various advantages over bioethanol and biodiesel. Biogenic residues with high ash content, like dry straw and wood, are the starting point for a four-step fuel syntheses process developed at the KIT, the bioliq ${ }^{\circledR}$ BTL process. ${ }^{[69]}$ The four steps are (i) fast pyrolysis of the biomass, (ii) entrained flow gasification, (iii) gas cleaning and conditioning, and finally (iv) fuel synthesis. Step three, gas cleaning and conditioning, consists of particle filtration, sourgas sorption, the removal of organics or ammonia $\left(\mathrm{NH}_{3}\right)$ and hydrogen cyanide $(\mathrm{HCN})$ and finally carbon dioxide $\left(\mathrm{CO}_{2}\right)$ removal. These processes are meant to take place at 80 bar and $500^{\circ} \mathrm{C}$ or $800^{\circ} \mathrm{C}$, respectively, and their performance might be enhanced by increasing the process temperature. ${ }^{[70,71]}$

Another field of possible application for tungsten laminate pipes is nuclear fusion. In the plasma of a fusion power reactor, the fusion of deuterium (D) with tritium (T) creates helium (He), frees a neutron (n) and releases $17.6 \mathrm{MeV}$ of energy (see Equation 4). ${ }^{[72]}$ 
To make a continuous operation possible, the plasma has to be cleaned of helium and impurities, such as particles from the first wall. These ions are redirected from the burning plasma towards cooled target plates; the plasma facing parts of the so-called divertors. Such divertors are exposed to heat loads of up to $20 \mathrm{MW} \mathrm{m}^{-2}$. Some divertor concepts make use of helium as a coolant $\left(600^{\circ} \mathrm{C}, 100 \mathrm{bar}\right)$ and ask for $\mathrm{W}$ materials to be used for structural cooling pipes. $^{[73]}$

It can be concluded that due to its high melting point, its excellent behavior towards liquid metals, molten salts and hot gases, tungsten would be a number one candidate for high temperature energy applications. Making use of the high toughness of tungsten foil, laminate pipes might have the potential to enhance the performance of innovative energy conversion systems or more visionary to bring new energy systems to life.

The aim of this paper is to present tungsten laminate pipes as well as their mechanical properties and their technical readiness, obtained and demonstrated by Charpy impact tests, burst tests performed at PLANSEE SE, as well as high heat flux (HHF) tests performed at the Plataforma Solar de Almería, Spain, and at the Max Planck Institute of Plasma Physics (IPP), Garching, Germany. So the following chapters will address the questions:

- What are the Charpy impact properties of W laminate pipes, and can these pipes be regarded as structural components?

- Is it possible to connect a W laminate pipe to a steel pipe in order to perform burst and HHF tests? 
- To what extent are the pipes ready and what challenges and open issues have to be addressed?

\section{W laminate pipes}

A tungsten pipe can be produced by extrusion; however, this appears to be challenging. Another possibility is drilling a hole in a tungsten rod. Due to the fabrication process of a tungsten rod, this semi-finished product has elongated grains in the axis direction, so the weak HAGBs are parallel to that axis direction. As known from the boiler formula, pressurized pipes are meant to fracture in the axis direction. So, for a pressurized tungsten pipe produced by drilling a hole in a rod, the preferred fracture direction due to the microstructure, meaning the weak HAGBs, is congruent to the expected fracture direction due to the stress state. So, a tungsten pipe made by drilling a hole in a rod for pressurized components can be regarded as a worst case scenario. The situation appears to be different if the tungsten pipe is made by the rolling up and joining of a tungsten foil. Now the grains follow the contour of the pipe, and the grain-boundary alignment can be realized. The weak HAGBs, meaning the direction with the low fracture toughness (see Figure 2), are now following the contour of the pipe and, by applying an internal pressure, the weak HAGBs are stressed by pressure only and not by tension. So with respect to the microstructure, a tungsten pipe for pressurized components made by rolling up a tungsten foil can be regarded as a best case scenario.

\subsection{Material and microstructure}

The material used for the synthesis of tungsten laminate pipes was technically pure tungsten (99.97 wt. \%) with a thickness of $100 \mu \mathrm{m}$. This commercially available material was produced by PLANSEE SE through a powder metallurgical process, consisting of sintering, 
and hot and cold rolling. In the as-received condition, this foil has pancake-shaped grains with a dimension of $0.5 \mu \mathrm{m} \times 3 \mu \mathrm{m} \times 15 \mu \mathrm{m}$, elongated in the rolling direction. The rolled foil has a pronounced rotated cube texture, $\{001\}<110>$, that appears to be the saturation texture, as this texture does not change by further rolling. By annealing this foil the texture becomes even more pronounced so tungsten foil exhibits selective grain growth (Figure 3). With regard to the stability of the microstructure, polygonization is meant to start at $900^{\circ} \mathrm{C}$ and recrystallization, in terms of the movement of HAGBs, is expected to start at $1200^{\circ} \mathrm{C} .{ }^{[47]}$ The mechanical properties of the $100 \mu \mathrm{m}$ tungsten foil can be interpreted by the texture of the foil, $\{001\}<110>$, the anisotropic grain shape, $0.5 \mu \mathrm{m} \times 3 \mu \mathrm{m} \times 15 \mu \mathrm{m}$, the preferred slip direction of the body-centered cubic metals, $<111>$, as well as the preferred crack direction of $\mathrm{W}$ at RT, the $\{100\}$ plane. ${ }^{[49]}$

The reason for the extraordinary mechanical properties of tungsten foil defines a still open question. The assessment of the authors gives hints that the ductility and toughness of the foil in the as-received condition are due to the high amount of mobile edge dislocations and the UFG microstructure, whereas the ductility of recrystallized tungsten foil benefits from dislocation annihilation on the free surface. ${ }^{[49]}$

\subsection{Synthesis of $W$ laminate pipes and connection to steel}

It is obvious that the mechanical properties of $\mathrm{W}$ laminate pipes depend on the condition of the tungsten foil after joining, as well as the condition of the interface of the tungsten foil and the interlayer. In this work, the synthesis of W laminate pipes is realized by brazing, ${ }^{[1,74]}$ defined as the melting of the interlayer. The interlayers used are an eutectic silver copper $(\mathrm{AgCu})$ brazing filler $\left(\mathrm{T}_{\mathrm{s}}=780^{\circ} \mathrm{C}\right)$, copper $\left(\mathrm{Cu}, \mathrm{T}_{\mathrm{s}}=1085^{\circ} \mathrm{C}\right)$, titanium $\left(\mathrm{Ti}, \mathrm{T}_{\mathrm{s}}=1668^{\circ} \mathrm{C}\right)$, and zirconium $\left(\mathrm{Zr}, \mathrm{T}_{\mathrm{s}}=1857^{\circ} \mathrm{C}\right)$. The thicknesses of the tungsten foil and the interlayer are $100 \mu \mathrm{m}$ each. The laminate pipes are made by rolling up one tungsten and one interlayer foil, 
fixing and brazing in a high vacuum. In this way, pipes with an outer diameter of $15 \mathrm{~mm}$, a wall thickness of about $0.8 \mathrm{~mm}$ and a length of $27 \mathrm{~mm}$ (Charpy impact test samples) or $70 \mathrm{~mm}$ (HHF tests) respectively, are produced.

Up to now, the fabrication of only straight pipes has been possible and the workability, such as welding and bending of $\mathrm{W}$ laminate pipes, has been poor. So, in order to produce testable components for burst and HHF tests, W laminate pipes have to be connected to steel pipes, generating the challenge of connecting two materials with difference coefficients of thermal expansion, $\alpha\left(\mathrm{W}, \alpha^{\mathrm{RT}-100^{\circ} \mathrm{C}}=4.2 * 10^{-6} \mathrm{~K}^{-1}\right.$, steel, $\alpha_{\text {austenitic }}{ }^{\mathrm{RT}-100^{\circ} \mathrm{C}}=16^{*} 10^{-6} \mathrm{~K}^{-1}, \alpha_{\text {ferritic }}$ martensitic ${ }^{\mathrm{RT}-100^{\circ} \mathrm{C}}=10.4^{*} 10^{-6} \mathrm{~K}^{-1}$ ). In this work, the $\mathrm{W}-\mathrm{Cu}$ and $\mathrm{W}-\mathrm{AgCu}$ laminate pipe are connected to austenitic steel pipes $(1.4571,316 \mathrm{Ti})$ by $\mathrm{Cu}$ or $\mathrm{AgCu}$ brazing respectively.

\section{Results of mechanical and HHF tests on W laminate pipes}

\subsection{Results of Charpy impact tests}

Charpy impact tests were performed according to DIN EN ISO 148-1 and 14556:2006-10 (see

also $^{[25]}$ ). Benchmark experiments were performed on $\mathrm{W}$ pipes made by drilling a hole in a rod. These pipes show brittle fracture and only dissipate a small amount of energy even at elevated temperatures such as $700^{\circ} \mathrm{C}$ (see Figure 4).

Similar results, obtained by W laminate pipes realized by brazing with zirconium, can be explained by the massive reaction of tungsten and zirconium during brazing leading to $\mathrm{W}$ solid solutions and intermetallic compounds. The situation looks different for tungstentitanium laminate pipes. Even if the tungsten foil is recrystallized after the joining process, these pipes are able to dissipate considerable amounts of energy even at RT. Excellent results can be obtained from laminate pipes made by brazing with copper or eutectic silver copper 
brazing filler. Due to the low brazing temperature, the tungsten foil is nearly in its as-received condition after joining. Furthermore, there is nearly no diffusion of tungsten in copper or silver and vice versa; so the interface shows excellent wettability but no formation of brittle tungsten solid solutions or intermetallic compounds. This explains why these pipes dissipate about $20 \mathrm{~J}$ in a Charpy test even at low temperatures and the test samples show plastic deformation but no brittle fracture (Figure 5). These results show that tungsten laminate pipes have the potential to be used as a structural material for pressurized components.

The next open issues are whether or not these pipes can be connected to steel pipes and how these pipes behave in a burst test, especially whether or not theses pipes show "leak before breach”.

\subsection{Result of a burst test (performed at PLANSEE SE)}

The burst test was performed on a tungsten laminate pipe made by brazing with eutectic silver copper brazing filler. This pipe is connected to austenitic steel pipes (1.4571) also by brazing with the same brazing filler. The first leak tests proved that the connection of the laminate pipe to the steel pipe was successful. The burst test was performed at RT by increasing the internal pressure using water. Due to the limitations of the burst test device, the test was stopped at an internal pressure of 1000 bar. The results of the burst test can be seen in Figure 6.

The laminate pipe did not explode and shows no residual damage. This result is astonishing, as the calculated stresses in the peripheral direction of the pipe (see boiler formula or BARLOW's formula) exceeded the tensile strength of the brazing filler. An explanation for this might be that either the laminate pipe benefits from the self-friction of the several layers 
or that the stress-strain distribution in the laminate pipe is not homogeneous, which might be beneficial for the pipe performance too.

The results of the Charpy and burst tests make tungsten laminate pipes a serious candidate for structural applications in the field of energy conversion.

\subsection{Preliminary results on HHF tests in a solar furnace (performed at the Plataforma}

\section{Solar de Almería, Spain)}

In the next step, the technical readiness of the pipes was demonstrated by HHF tests. The pipes tested were $\mathrm{W}-\mathrm{Cu}$ and $\mathrm{Mo}-\mathrm{Cu}$ laminate pipes connected to austenitic steel (1.4571) by Cu brazing. For high absorbance (85 \% - $90 \%$ ) and low reflectance, the pipes were given a black surface-coating by physical vapor deposition. In doing this, a $13 \mathrm{~nm} \mathrm{~W}$ oxide layer was removed by plasma etching resulting in a high quality clean surface onto which, finally, the black surface was deposited. The adhesion of the black surface to the $\mathrm{W}$ laminate pipe was excellent and oxidation tests proved the working range of the layer of up to $700^{\circ} \mathrm{C}$ in air. Pipes produced like this were tested at the Plataforma Solar de Almería in a solar furnace. The cooling media was water at RT, $1.26 \mathrm{bar}, 9 \mathrm{l} \mathrm{min}^{-1}$ and the heat load was $4.5 \mathrm{MW} \mathrm{m}$. The pipes were able to withstand this heat load for hours, as was the black surface as the surface temperature did not exceed $700^{\circ} \mathrm{C}$ (Figure 7).

These results show that $\mathrm{W}-\mathrm{Cu}$ or Mo-Cu laminate pipes are a serious candidate for pipe receivers, especially when using liquid metal cooling.

\subsection{Results of HHF tests with plasma heat (performed at IPP Garching, Germany)}

Using a W laminate pipe as a structural pipe with water coolant in the pressurized water reactor condition $\left(275^{\circ} \mathrm{C}-325^{\circ} \mathrm{C}, 160\right.$ bar $)$, the $\mathrm{W}$ pipe has to be protected from corrosion by 
a layer of austenitic steel. The question now arises as to whether or not it is possible to fabricate a testable mockup consisting of a W laminate pipe surrounding an austenitic steel pipe.

The mockup produced and tested at IPP Garching consists of an austenitic steel pipe, 1.4571 (316Ti), with a diameter of $15 \mathrm{~mm}$ and a wall thickness of $1 \mathrm{~mm}$. This pipe is surrounded by a W-Cu laminate pipe and joined to a tungsten saddle by copper brazing (Figure 8). Especially when using this type of mockup for nuclear fusion application, an amour component like a W saddle or a $\mathrm{W}$ monoblock is a must due to the ion and $\alpha$-particle bombardment, resulting in an expected sputtering rate of up to $5 \mathrm{~mm}$ in 2 full power years.

In this configuration, the $\mathrm{W}$ laminate pipe has two functions: (i) to be a structural component and (ii) to be a functional component dealing with the different coefficients of thermal expansion of the austenitic steel pipe and the $\mathrm{W}$ saddle.

The successful fabrication of a testable mockup can be seen in Figure 8 and HHF tests were performed in a device called GLADIS (Garching Large Divertor Sample Test Facility) at the IPP in Garching, Germay. ${ }^{[75,76]}$

The cooling media was water at RT with 10 bar, a flow velocity of $10 \mathrm{~m} \mathrm{~s}^{-1}$ and a flow rate of $1.13 \mathrm{l} / \mathrm{s}^{-1}$. The mockup was exposed to a cyclic heat load of $6 \mathrm{MW} \mathrm{m}^{-2}$. The duration of one cycle was one minute and consisted of a $20 \mathrm{~s}$ beam on and a $40 \mathrm{~s}$ beam off. After 100 cycles, the mockup was still completely fine showing no residual damage. During the whole test campaign, the temperatures in the tungsten saddle remained the same cycle by cycle (e.g. max. surface temperature: $\mathrm{T}_{\max }=1085^{\circ} \mathrm{C}$ ), indicating that there was no degradation of the mockup and the joined parts. However, by increasing the heat flux up to $7 \mathrm{MW} \mathrm{m}^{-2}$, the temperature in the tungsten saddle increased, cycle by cycle, indicating that some damage appeared in the mockup. Post examination of the mockup showed that the $7 \mathrm{MW} \mathrm{m}^{-2}$ heat load caused the melting of the copper foil. 
It can be concluded that, even in such an extreme condition of a W laminate pipe surrounding an austenitic steel pipe, the $\mathrm{W}$ laminate pipe can excellently deal with the thermal mismatch and that testable mockups can be produced.

\subsection{Discussion of the results and strategies}

The results of the Charpy, burst and HHF tests make it possible to define strategies for the synthesis of high performance tungsten laminate pipes. These are, on the one hand, laminates with a high thermal conductivity such as W-Cu laminates, and, on the other hand, high temperature laminates.

If a W laminate pipe is meant to be used as a receiver in towers or furnaces in the field of CSP, a high thermal conductivity laminate pipe might be the best option as high thermal conductivity results in the fast removal of the heat load. Furthermore, if the thermal conductivity in the plane is higher than through plane then the temperature distribution appears to be more homogeneous in the pipe resulting in a reduced temperature gradient and, therefore, reduced secondary stresses. Such high thermal conductivity laminate pipes can be realized by synthesizing a tungsten-copper laminate. The thermal conductivity at RT of tungsten is about $164 \mathrm{~W} \mathrm{~m}^{-1} \mathrm{~K}^{-1}$ and of copper about $390 \mathrm{~W} \mathrm{~m}^{-1} \mathrm{~K}^{-1}$. So, according to the linear and inverse rule of mixture, a laminate pipe made of 50 vol. \% tungsten and 50 vol. \% copper is expected to have a through-plane thermal conductivity of $231 \mathrm{~W} \mathrm{~m}^{-1} \mathrm{~K}^{-1}$ and an inplane thermal conductivity of $277 \mathrm{~W} \mathrm{~m}^{-1} \mathrm{~K}^{-1} \cdot{ }^{[74]}$ As there is nearly no diffusion of $\mathrm{W}$ in $\mathrm{Cu}$ and vice versa, the aging of the interface is not an issue. So, especially in terms of CSP with liquid metal coolant, $\mathrm{W}$ laminate pipes might perform better compared to high performance steels and Ni-base super alloys due to their high thermal conductivity and excellent behavior towards liquid metals.

If a W laminate pipe is meant to be used as a high temperature pipe for gas cleaning processes (BTL) or for a dish/Stirling device (CSP) than a high temperature laminate pipe might be the 
best option. In this case, interlayers of palladium $\left(\mathrm{T}_{\mathrm{m}}=1555^{\circ} \mathrm{C}\right)$, titanium $\left(\mathrm{T}_{\mathrm{m}}=1668^{\circ} \mathrm{C}\right)$, vanadium $\left(\mathrm{T}_{\mathrm{m}}=1910^{\circ} \mathrm{C}\right)$ or no interlayer at all can be chosen. In the case of direct diffusion bonding without any interlayer, the foil surfaces can be activated by some atomic layers of titanium, nickel or niobium.

In any case, the joining temperature and the operation temperature of a $\mathrm{W}$ laminate pipe must be below the recrystallization temperature of the foil. Here, potassium (K) doped W foil (W with $20-70 \mathrm{ppm} \mathrm{K}$ ) is meant to shift the recrystallization temperature from $1100^{\circ} \mathrm{C}$ to about $1400^{\circ} \mathrm{C}$, compared to pure tungsten foil (thickness of the foils is $100 \mu \mathrm{m}$ each), as the potassium is surrounding the grains stabilizing the UFG microstructure. According to this grain-boundary stabilizing mechanism, the higher the degree of deformation, the more finely dispersed the potassium bubbles, the higher the recrystallization temperature. In addition potassium doped W shows an enhanced creep performance. ${ }^{[77]}$ Possible joining technologies for high temperature laminate pipes are hot radial pressing or hot isostatic pressing. Furthermore, due to severe oxidation difficulties, the $\mathrm{W}$ laminate pipes do have to be either used in a vacuum vessel (see e.g. BTL, hot gas cleaning, nuclear fusion) or have to be coated with an oxidation protection layer (see e.g. CSP).

\section{Conclusions}

The aim of this paper was to present the proof-of-principle of the vision to produce a tungsten pipe with high toughness and ductility that meets the requirements for a structural material. Making use of the unique property of $\mathrm{W}$ that is that the BDT can be shifted to lower temperatures by cold working, a tungsten foil with a BDTT below $-120^{\circ} \mathrm{C}$ and a RT fracture toughness of $70 \mathrm{MPa} \mathrm{m}{ }^{1 / 2}$ was the starting point of the synthesis of a tungsten laminate pipe. These pipes might increase the operation window of current state-of-the-art high temperature pipe materials like 9-12 wt. \% Cr steels (P91, P92) and nickel-base super alloys and, 
therefore, have the potential to increase the performance of innovative high temperature energy conversion systems like CSP and solar chemistry, AMTEC, BTL processes, and nuclear fusion.

From the scientific point of view, W laminates offer several interesting questions. These are the identification of the mechanism of the plastic deformation of UFG $\mathrm{W}$ foil, the assessment of the anisotropy of the fracture toughness combined with the determination of the activation energy of the BDT, as well as the synthesis and characterization of $\mathrm{W}$ laminates with interlayers smaller than $1 \mu \mathrm{m}$. The main scientific question, however, is why the BDTT can be shifted to lower temperatures by cold working. To answer this question, however, requires identifying the controlling mechanism of the BDT in general. But up to now, it has not been clear whether or not the BDT is a dislocation nucleation or a dislocation glide controlled event.

From the technical point of view, the synthesis of high temperature laminate pipes using a high melting interlayer or no interlayer at all appears to be the next challenge. These syntheses have to take place below the recrystallization temperature of the foil, meaning by, for example, hot radial pressing. For technical applications the potassium (K) doped tungsten foil (W with 20-70 ppm K) has to be preferred to pure tungsten foil as the doped foil is meant to shift the recrystallization temperature from $1100^{\circ} \mathrm{C}$ to about $1400^{\circ} \mathrm{C}$. Further open questions are the behavior of the connection from $\mathrm{W}$ laminate pipe to steel under thermal cyclic loading (ratcheting or shakedown), the low cycle fatigue behavior of UFG materials, the creep behavior, aging with respect to the KIRKENDALL effect, as well as, if the pipe is not used in a vacuum, the assessment of the performance of an oxidation protection layer. Current state-of-the-art oxidation protection layers are coatings based on silicon and boron which are applied by atmosphere plasma spraying. These coatings have the potential to protect the material for about $10000 \mathrm{~h}$ at $1100^{\circ} \mathrm{C}$ in air. 
Tungsten is a material of extremes. By using tungsten pipes made of high toughness tungsten foils the performance of innovative energy conversion systems might be shifted to the next level.

Received: ((will be filled in by the editorial staff))

Revised: ((will be filled in by the editorial staff)) Published online: ((will be filled in by the editorial staff))

[1] J. Reiser, M. Rieth, B. Dafferner, A. Hoffmann, J. Nucl. Mater. 2012, 423, 1.

[2] D. M. Berczik, US 5595 616, 1997.

[3] D. M. Berczik, US 5693 156, 1997.

[4] P. Jéhanno, M. Heilmaier, H. Kestler, Intermetallics 2004, 12, 1005.

[5] Y. Xu, Z. Zhou, M. Li, P. He, J. Nucl. Mater. 2011, 417, 283.

[6] P. Schloth, M. A. Weisser, H. Van Swygenhoven, S. Van Petegem, P. Susila, V.

Subramanya Sarma, B. S. Murty, S. Lauterbach, M. Heilmaier, Scripta Mater. 2012, 66, 690.

[7] M. J. Alinger, G. R. Odette, D. T. Hoelzer, Acta Mater. 2009, 57, 392.

[8] A. Hirata, T. Fujita, Y. R. Wen, J. H. Schneibel, C. T. Liu, M. W. Chen, Nat. Mater. 2011, 10, 922.

[9] R. Lindau, A. Möslang, M. Schirra, P. Schlossmacher, M. Klimenkov, J. Nucl. Mater. 2002, 307, 769.

[10] J. L. Walter, H. E. Cline, Metall. Trans. 1970, 1, 1221.

[11] J.-M. Yang, S. M. Jeng, K. Bain, R. A. Amato, Acta Mater. 1997, 45, 295.

[12] M. Dudová, K. Kucharová, T. Barták, H. Bei, E. P. George, C. Somsen, A. Dlouhy, Acta Mater. 2011, 65, 699.

[13] H. Bei, E. P. George, Acta Mater. 2005, 53, 69. 
[14] W. J. Quadakkers, N. L. Wijnandsrade, V. Shermet, L. Singheiser, DE 10025108 A1, 2001.

[15] D. S. T. Magyar, E. C. Hirakis, M. L. Gell, E. J. Felten, US 4078 922, 1978.

[16] E. J. Opila, R. E. Hann, J. Am. Ceram. Soc., 1997, 80, 197.

[17] L. L. Snead, T. Nozawa, Y. Katoh, T.-S. Byun, S. Kondo, D. A. Petti, J. Nucl. Mater. 2007, 371, 329.

[18] E. Lassner, W.-D. Schubert, Tungsten - Properties, Chemistry, Technology of the Element, Alloys and Chemical Compounds, Kluwer Academic, New York, USA 1999.

[19] www.plansee.com (2013).

[20] A. Giannattasio, M. Tanaka, T. D. Joseph and S. G. Roberts, Phys. Scripta 2007, T128, 87.

[21] P. Gumbsch, J. Nucl. Mater. 2003, 323, 304.

[22] E. O. Hall, Proc. Phys. Soc. 1951, B 64, 747.

[23] N. J. Petch, I. Iron Steel Inst. 1953, 174, 25.

[24] D. Rupp, S. M. Weygand, Philos. Mag. 2010, 90, 4055.

[25] M. Rieth, A. Hoffmann, Int. J. Refract. Met. H. 2010, 28, 679.

[26] Tran-Huu-Loi, J. P. Morniroli, M. Gantois, M. Lahaye, J. Mater. Sci. 1985, 20, 199.

[27] B. Gludovatz, S. Wurster, T. Weingartner, A. Hoffmann, R. Pippan, Philos. Mag. 2011, 91, 1.

[28] J. Neges, B. Ortner, G. Leichtfried, H. P. Strüwe, Mater. Sci. Eng. A 1995,196, 129.

[29] A. Giannattasio, S. G. Roberts, Philos. Mag. 2007, 87, 2589.

[30] J. Riedle, P. Gumbsch, H. F. Fischmeister, Phys. Rev. Lett. 1996, 76, 3594.

[31] P. Gumbsch, J. Riedle, A. Hartmaier, H. F. Fischmeister, Science 1998, 282, 1293.

[32] L. Romaner, C. Ambrosch-Draxl, R. Pippan, Phys. Rev. Lett. 2010, 104, 195503.

[33] S. Wurster, B. Gludovatz, R. Pippan, Int. J. Refract. Met. H., 2010, 28, 692.

[34] M. Rieth, D. E. J. Armstrong, B. Dafferner et al., Adv. Sci. Tech., 2010, 73, 11. 
[35] M. Rieth, J. Reiser, B. Dafferner, S. Baumgärtner, Fusion Sci. Technol. 2012, 61, 381.

[36] M. Faleschini, H. Kreuzer, D. Kiener, R. Pippan, J. Nucl. Mater. 2007, 367, 800.

[37] M. Faleschini, W. Knabl, R. Pippan, Fract. Nano Eng. Mater. Struct. 2006, 15, 445.

[38] H. Kurishita, S. Matsuo, H. Arakawa et al., Mater. Sci. Eng. A 2008, 477, 162.

[39] H. Kurishita, S. Matsuo, H. Arakawa et al., J. Nucl. Mater. 2010, 398, 87.

[40] J. Hohe, P. Gumbsch, J. Nucl. Mater. 2010, 400, 218.

[41] V. Livramento, D. Nunes, J. B. Correia, P. A. Carvalho, R. Mateus, K. Hanada, N. Shohoji, H. Fernandes, C. Silva, E. Alves, presented at ENMAT 2010, Karlsruhe, Germany $(07,2010)$.

[42] J. Du, T. Höschen, M. Rasinski, S. Wurster, W. Grosinger, J. H. You, Compos. Sci. Technol. 2010, 70, 1482.

[43] B. Gludovatz, S. Wurster, A. Hoffmann, R. Pippan, Int. J. Refract. Met. H. 2010, 28, 674.

[44] Annual Book of ASTM Standards - Standard Test Method for Plane-Strain Fracture Toughness of Metallic Materials (ASTM E 399-90), vol. 03.01. American Society for Testing and Materials 1997.

[45] R. Pippan, presented at W conference, organized by G. R. Odette, UCLA, Santa Barbara, USA (02, 2011).

[46] E. Arzt, Acta Mater. 1998, 46, 5611.

[47] J. Reiser, M. Rieth, B. Dafferner, A. Hoffmann, X. Yi, D. E. J. Armstrong, J. Nucl. Mater. 2012, 424, 197.

[48] M. A. Meyers, A. Mishra, D. J. Benson, Prog. Mater. Sci. 2006 51, 427.

[49] J. Reiser, M. Rieth, A. Möslang, B. Dafferner, A. Hoffmann, X. Yi, D. E. J. Armstrong, J. Nucl. Mater. 2013, 434, 357.

[50] T. L. Anderson, Fracture Mechanics - Fundamentals and Applications, CRC Press, Boca Raton, USA 1995. 
[51] J. W. Menter, D. W. Pashley, The microstructure and mechanical properties of thin films, presented at Struct. Prop. Thin Films: Proc. Int. Conf., Bolton Landing, New York, USA (09, 1959).

[52] J. A. Duffie, W. A. Beckman, Solar Engineering of Thermal Processes, John Wiley \& Sons, Inc., New York, USA 1991.

[53] V. R. Hernández, La Electricidad Termosolar - Solar Thermal Power, Protermosolar, Sevilla, Spain, 1991.

[54] J. I. Burgaleta, S. Arias, D. Ramirez, Gemasolar, the first Tower Thermosolar Commercial Plant with Molten Salt Storage, $17^{\text {th }}$ International Symposium on Concentrating Solar Power and Chemical Energy Systems (SolarPACES), Granada, Spain (09, 2011). [55] P. Heller, J. Jedamski, L. Amsbeck, R. Uhlig, M. Ebert, M. Svensson, T. Denk, C. Hilgert, U. Fisher, J. Sinai, C. Gertig, P. Tochon, Development of a Solar-Hybrid Microturbine System for a Mini-Tower, $15^{\text {th }}$ International Symposium on Concentrating Solar Power and Chemical Energy Systems (SolarPACES), Berlin, Germany (09, 2009).

[56] T. Keck, W. Schiel, P. Heller, W. Reinalter, J.-M. Gineste, A. Ferriere, G. Flamant, Eurodish - Continous Operation, System Improvement and Reference Units, $13^{\text {th }}$ International Symposium on Concentrating Solar Power and Chemical Energy Systems (SolarPACES), Sevilla, Spain (06, 2006).

[57] T. Denk, A. Valverde, R. Diaz, J. F. Soler, A. Vidal, CRS-SSPS Solar Tower: A 2.7 MW Remodeled Test-Bed for Solar Thermochemical Hydrogen Production, $18^{\text {th }}$ International Symposium on Concentrating Solar Power and Chemical Energy Systems (SolarPACES), Marrakech, Morocco (09, 2012).

[58] A. Houaijia, C. Sattler, M. Roeb, M. Lange, S. Breuer, J. P. Säck, Reactor Design and Process Simulation of a Two-Step Thermochemical Cycle for Solar Hydrogen Production from Water, $18^{\text {th }}$ International Symposium on Concentrating Solar Power and Chemical Energy Systems (SolarPACES) Marrakech, Morocco (09, 2012). 
[61] C. L. Muhich, B. W. Evanko, K. C. Weston, P. Lichty, X. Liang, J. Martinek, C. B. Musgrave, A. W. Weimer, Science 2013, 341, 540.

[62] K. Omori, N. Gokon, T. Hatamachi, T. Kodama, Two-Step Switching Test of WaterSplitting Process Using Internally Circulating Fluidized Bed Reactor, $18^{\text {th }}$ International Symposium on Concentrating Solar Power and Chemical Energy Systems (SolarPACES) Marrakech, Morocco (09, 2012).

[63] W. Hering, R. Stieglitz, T. Wetzel, Application of liquid metals for solar energy systems, presented at European Energy Conference, E2C, Maastricht (04, 2012).

[64] T. Cole, Science, 1983, 221, 915.

[65] S. Wu, L. Xiao, Y. Cao, Int. J. Energ. Res. 2009, 33, 868.

[66] W. Hering, N. Díez de los Ríos, J. Konys, G. Müller, A. Onea, J. Reiser, R. Stieglitz, A. Weisenburger, Materials for direct energy conversion, presented at ENMAT Conference, Karlsruhe, Germany $(05,2013)$.

[67] W. Hering, R. Stieglitz, A. Jianu, M. Lux, A. Onea, C. Homann, Scientific Program of the Karlsruhe Sodium Facility (KASOLA), presented at OECD-meeting FR13, Paris, France $(03,2013)$.

[68] www.inr.kit.edu (2013).

[69] N. Dahmen, E. Dinjus, T. Kolb, U. Arnold, H. Leibold, R. Stahl, Environ. Prog. 2012, 31, 176.

[70] www.bioliq.de (2013).

[71] H. Leibold, R. Mai, A. Linek, J. Stöhr, H. Seifert, HTHP syngas cleaning in the bioliq BtL process, presented at the 5th International Freiberg Conference on IGCC \& XtL Technologies (IFC), Leipzig, Germany (05, 2012).

[72] E. Rebhan, D. Reiter, R. Weynants, U. Samm, W. J. Hogan, J. Raeder, T. 
Hamacher, Controlled nuclear fusion: general aspects, in: K. Heinloth (Editor), Landolt-

Bornstein Numerical, Data and Functional Relationships in Science and Technology, Group

VIII: Advanced Materials and Technologies, Vol. 3. Energy Technologies, Subvolume B:

Nuclear Energy, Berlin, Heidelberg, New York, Springer, 2005.

[73] J. Reiser, M. Rieth, Fusion Eng. Des. 2012, 87, 718.

[74] J. Reiser, M. Rieth, A. Möslang, B. Dafferner, J. Hoffmann, T. Mrotzek, A.

Hoffmann, D. E. J. Armstrong, X. Yi, J. Nucl. Mater. 2013, 436, 47.

[75] H. Greuner, H. Bolt, B. Böswirth, T. Franke, P. McNeely, S. Obermayer, N. Rust, R. Süß, Fusion Eng. Des. 2005, 75, 345.

[76] H. Greuner, B. Böswirth, J. Boscary, P. McNeely, J. Nucl. Mater. 2007, 417, 481.

[77] E. Pink, L. Bartha, Metallurgy of Doped/Non-Sag Tungsten, Springer, 1989.
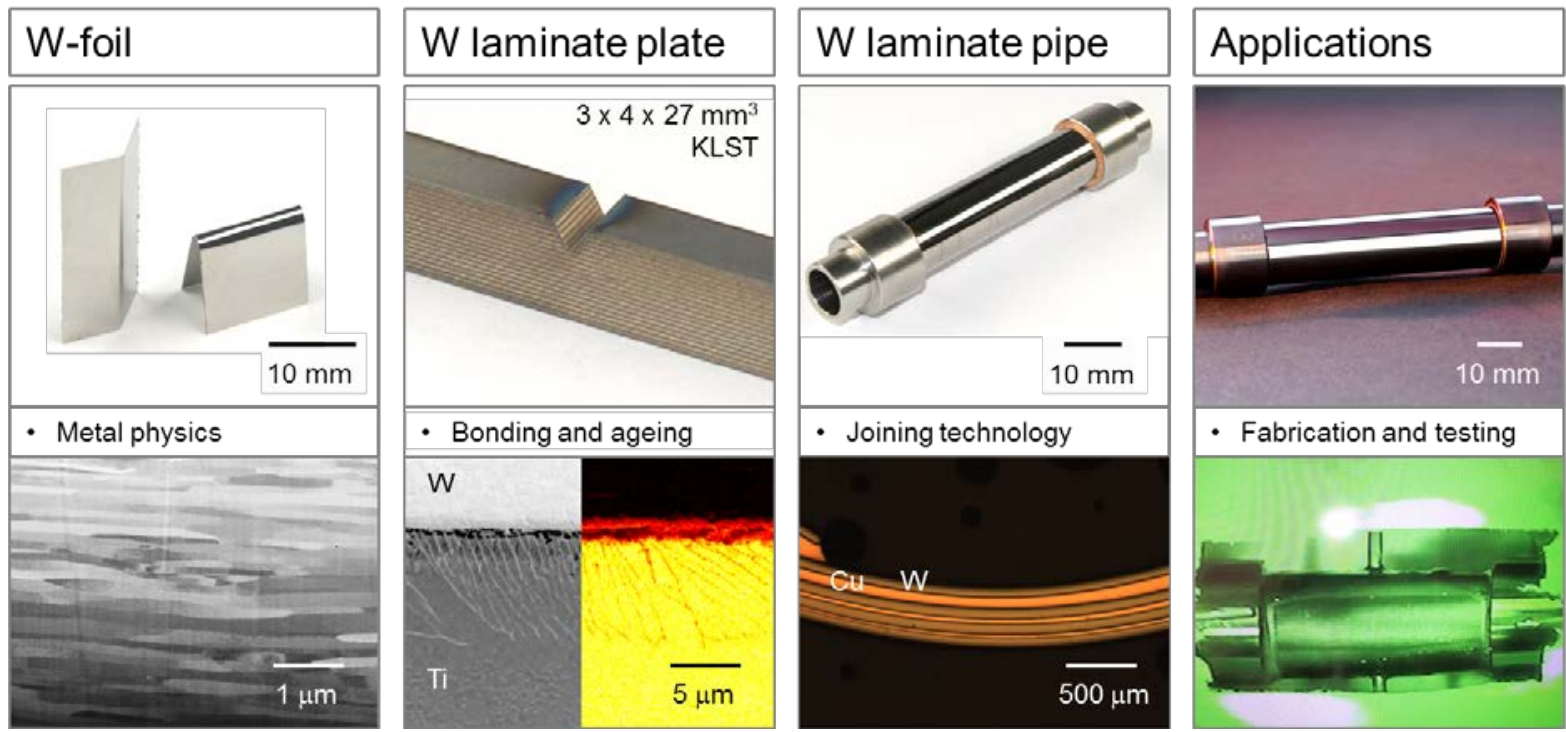

Fig. 1. From the left to the right: The extraordinary mechanical properties of $W$ foil that can be related to its UFG microstructure. Through the synthesis of a W laminate the mechanical properties of the foil can be transferred to the bulk. Furthermore, by rolling up and joining of a foil a W laminate pipe can be produced that appears to be an interesting candidate for high temperature structural applications in the field of energy conversion. 


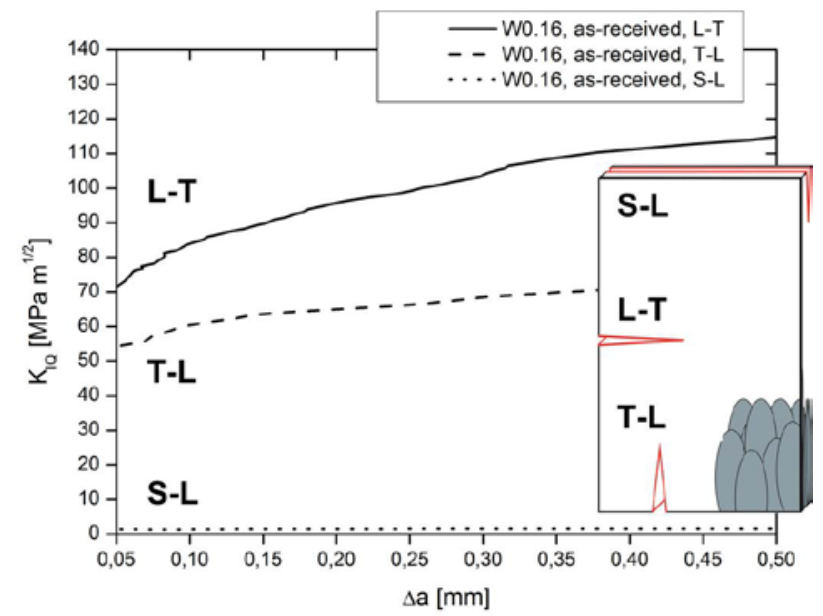

Fig. 2. $R$ curve, showing the RT fracture toughness, KIQ, of $160 \mu \mathrm{m}$ thick tungsten foil in the as-received condition, determined by the potential method. $\Delta a$ is the crack extension. The fracture toughness is extremely anisotropic with high values in the plane direction (L-T, T-L) of the foil. The low fracture toughness in the S-L direction can be related to the low GBs cohesion.
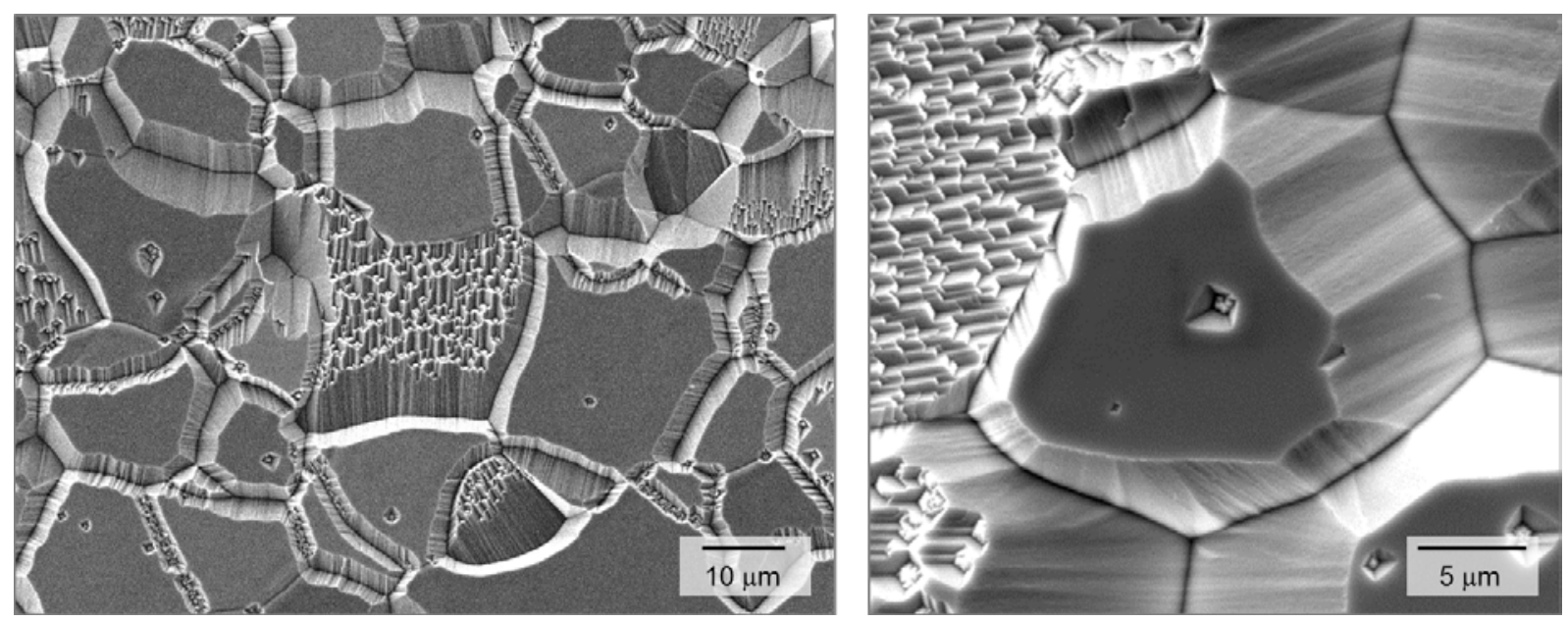

Fig. 3. $100 \mu$ m thick tungsten foil has a pronounced texture in $\{001\}<110>$, that becomes even more pronounced by annealing. In tungsten, dislocations penetrating the surface can be made visible by etch pitting. ${ }^{[31]}$ This process is highly anisotropic and gives best results on $\{001\}$ surfaces. This picture shows the top view of annealed $\left(2 \mathrm{~h}\right.$ at $\left.1800^{\circ} \mathrm{C}\right)$ and etched tungsten foil. The penetrating forest dislocations on the $\{001\}$ surfaces are clearly visible and are further proof of the pronounced rotated cube texture. 


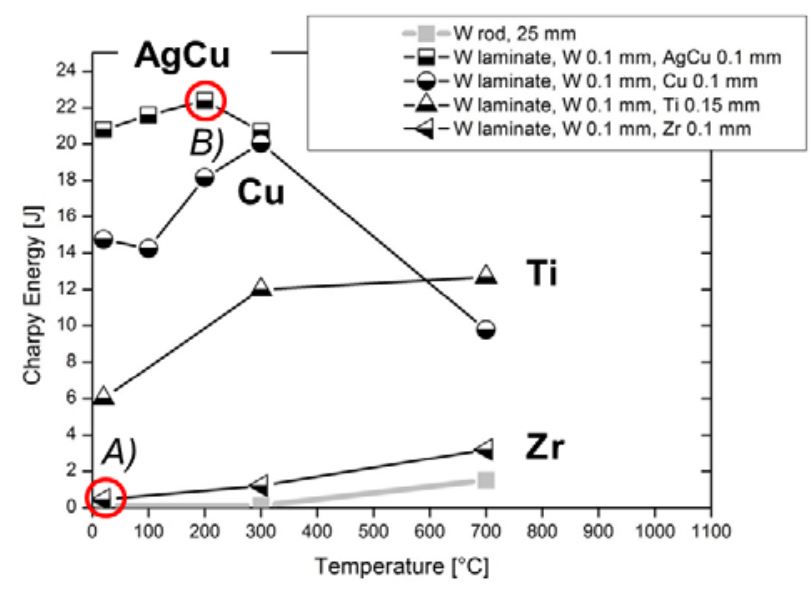

Fig. 4. This diagram shows the results of Charpy impact tests performed on W laminate pipes produced by brazing with different interlayers. The pipes had an outer diameter of $15 \mathrm{~mm}, 0.8$ $\mathrm{mm}$ wall thickness and $27 \mathrm{~mm}$ length on a $22 \mathrm{~mm}$ span. The results are benchmarked on a W pipe made by drilling a hole in a $W$ rod.
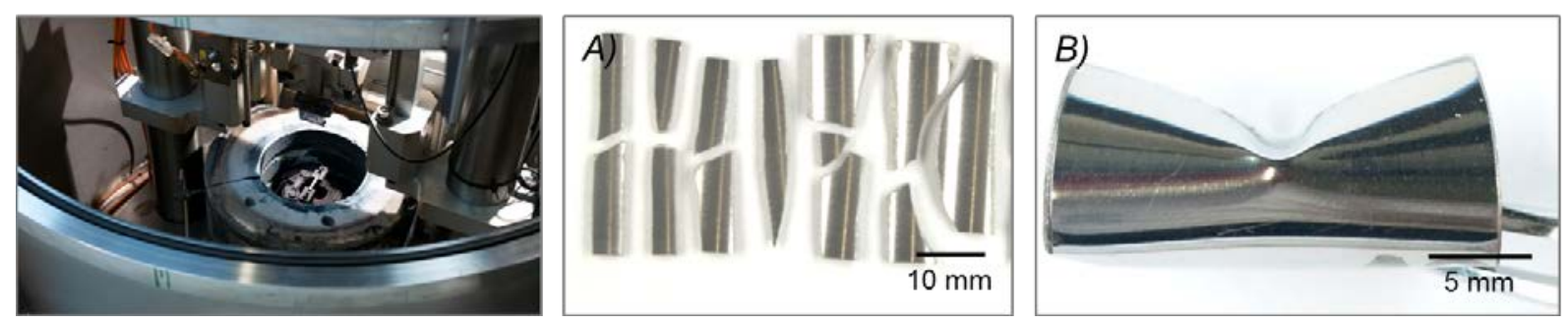

Fig. 5. A tungsten pipe, made by drilling a hole in a rod, fractures brittle (A) and can hardly dissipate energy even at $700^{\circ} \mathrm{C}$. The situation appears different for tungsten laminate pipes made by the rolling up and joining of a tungsten foil. These pipes are able to dissipate high amounts of energy (B) even at RT.
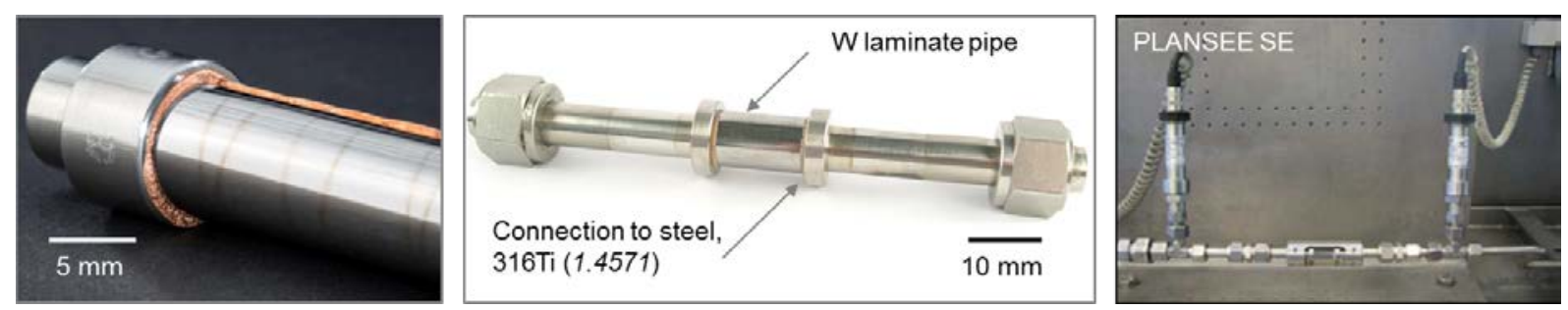

Fig. 6. Left: Tungsten laminate pipes can be joined to austenitic steel (1.4571) and burst test samples and HHF test samples can be produced. Middle: This picture shows the burst test sample after the test. The pipe shows no residual damage after 1000 bar at RT. Right: Test configuration and burst test device at PLANSEE SE. 

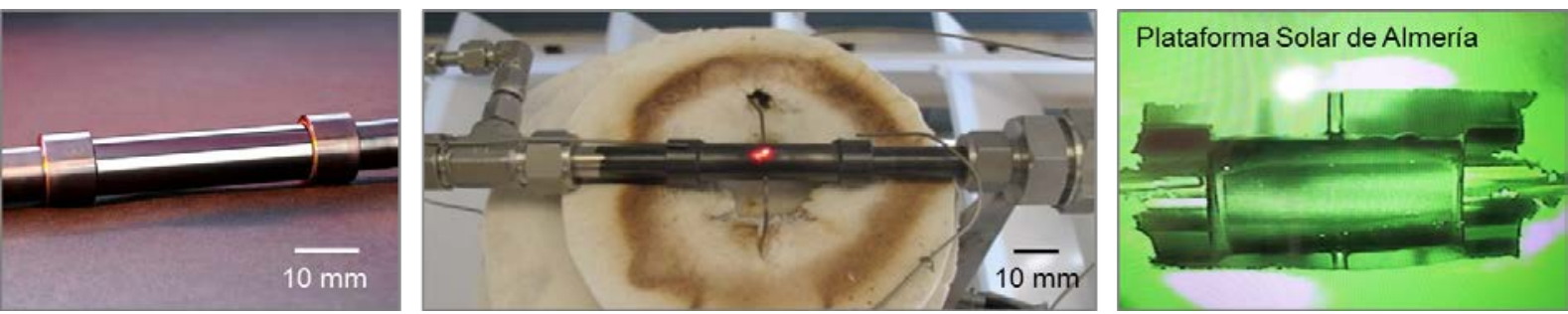

Fig. 7. Left: A W-Cu laminate pipe with a length of $70 \mathrm{~mm}$ is coated with a black surface ready for HHF tests. Middle: Configuration of the HHF test device at the Plataforma Solar de Almería. Right: Observation of the HHF tests during operation. The results show, that a heat load of least $4.5 \mathrm{MW} \mathrm{m}^{-2}$ can be removed and that the black coated surface works well up to at least $700^{\circ} \mathrm{C}$ in air.
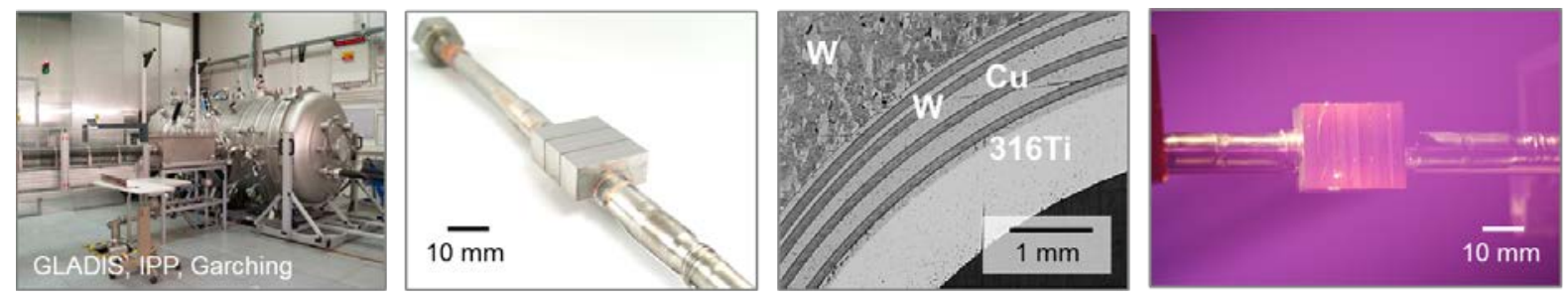

Fig. 8. From the left to the right: In an HHF test device called GLADIS at the IPP in Garching, mockups containing a W-Cu laminate pipe surrounding an austenitic steel pipe (1.4571) joined to a tungsten saddle were tested. The results show, that a heat load of least 6 $M W m^{-2}$ can be removed.

\section{The table of contents}

By cold working the brittle-to-ductile transition temperature (BDTT) of tungsten can be shifted to lower temperatures. The authors make use of this fact by using a tungsten foil for the synthesis of tungsten laminate pipes. These pipes show extraordinary mechanical properties and are a serious candidate to be used in innovative high temperature energy conversion systems (Fig. 1).

Jens Reiser,* Michael Rieth, Anton Möslang, Henri Greuner, David E. J. Armstrong, Thorsten Denk, Tim Gräning, Wolfgang Hering, Andreas Hoffmann, Jan Hoffmann, Harald Leiste, Tobias Mrotzek, Reinhard Pippan, Werner Schulmeyer, Tobias Weingärtner and Anton Zabernig.

\section{Tungsten (W) Laminate Pipes for Innovative High Temperature Energy Conversion Systems}

